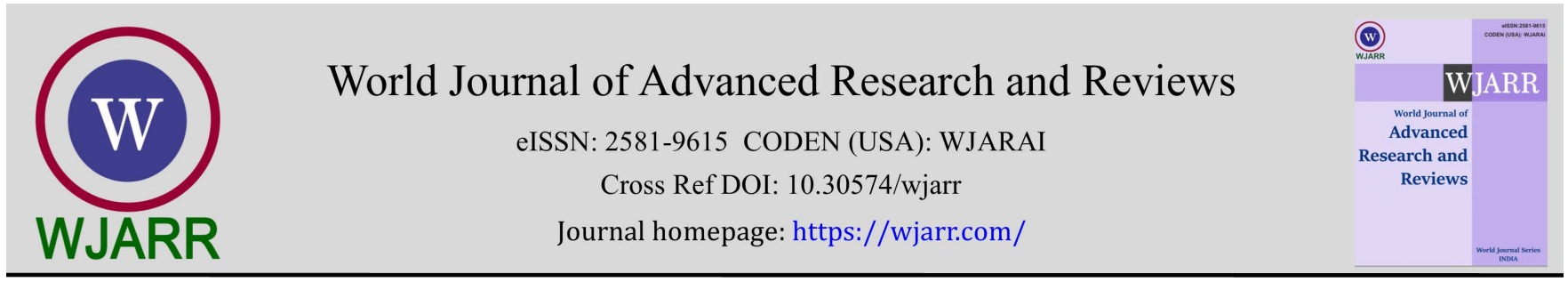

(REVIEW ARTICLE)

Check for updates

\title{
Genome wide association mapping of yield and other agronomic traits in rice: Narrative literature review
}

Muhammad Asad 1, *, Izzah Ihsan 2, Muther Mansoor Qaisrani 4, Hafiz Muhammad Zeeshan Raza ${ }^{3}$ and Jallat Khan 5

${ }^{1}$ Department of Bioscience \& Technology, Khwaja Fareed University of Engineering \& Information Technology, Punjab, Pakistan.

2 Department of Botany, University of Agriculture Faisalabad, Punjab, Pakistan

${ }^{3}$ Genomics and Computational Biology Laboratory, COMSATS University Islamabad, Sahiwal Campus, Punjab, Pakistan.

${ }^{4}$ Department of Bioscience \& Technology, Khwaja Fareed University of Engineering \& Information Technology, Punjab, Pakistan.

${ }^{5}$ Department of Chemistry, Khwaja Fareed University of Engineering \& Information Technology, Punjab, Pakistan.

World Journal of Advanced Research and Reviews, 2021, 12(03), 354-367

Publication history: Received on 09 November 2021; revised on 18 December 2021; accepted on 20 December 2021

Article DOI: https://doi.org/10.30574/wjarr.2021.12.3.0695

\begin{abstract}
Based on previous recombination actions and LD (linkage disequilibrium) throughout the genome, genome wide association mapping studies often are employed to find Quantitative trait locus in varied collections of crop germplasm. Generally, diverse panel's genotyped using high density Single nucleotide polymorphism (SNP) panels are used to test a broad variety of haplotypes and alleles, as well as to track recombination divisions throughout the genome. GWAS, on the other hand, have rarely been used in breeding populations. We studied association mapping for agricultural parameters such as yield and its constituents in a breeding inhabitants of top irrigated tropical rice progenies so that the findings could be used to breeding more directly than those from a diverse panel. GWAS was undertaken with the specific purpose of accelerating selection in the breeding population, and the sample was genotyped with 71,710 Single nucleotide polymorphisms using genotyping-by-sequencing. We found 52 Quantitative trait locus QTL for 11 agronomic characteristics using this breeding panel, including substantial impact Quantitative trait loci (QTLs) for flowering period as well as grain width, grain length, grain length-breadth ratio. Furthermore we discovered haplotypes that may be applied to choose plants for our population with smaller stature (plant height), fast blooming time, with high yield, demonstrating the value of association mapping for advising breeding choices in breeding populations. Furthermore, we explore at how genomic-assisted selection models might be built using the newly discovered important Single nucleotide polymorphisms (SNPs) and deep insight into the genetic structure of these quantitative traits.
\end{abstract}

Keywords: Rice; Genome wide association; SNPs; NGS; QTLs; Bioinformatics

\section{Introduction}

Rice is the seed of the grass species Oryza sativa, the term wild rice is typically used for species of the genera Porteresia \& Zizania, both wild and domesticated, though the word may also be used for uncultivated or primitive varieties of Oryza. As a cereal grain, domesticated rice is the most widely consumed staple food for over half of the world's human population, especially in Africa \& Asia. The agricultural product with the $3^{\text {rd }}$-highest worldwide production, after maiz \& sugarcane [1]. Since sizable portions of maize and sugarcane crops are used for purposes other than human consumption, rice is the most important food crop with regard to human nutrition and caloric intake, providing more than one-fifth of

\footnotetext{
${ }^{*}$ Corresponding author: Muhammad Asad

Department of Bioscience \& Technology, Khwaja Fareed University of Engineering \& Information Technology, Punjab, Pakistan.

Copyright (C) 2021 Author(s) retain the copyright of this article. This article is published under the terms of the Creative Commons Attribution Liscense 4.0.
} 
the calories consumed worldwide by humans [2]. There are many varieties of rice and culinary preferences tend to vary regionally.

The traditional method for cultivating rice is flooding the fields while, or after, setting the young seedlings. This method needs sound irrigation planning but reduces the growth of less robust pest and weed plants that have no submerged growth state, and deters insects. While overflowing is not obligatory for the cultivation of rice, all other approaches of irrigation require higher effort in weed and pest control during development stages and a different approach for fertilizing the soil. Cooked brown rice from Bhutan Jumli Marshi, brown rice from Nepal Rice can come in many shapes, colors and sizes.

Single grain of rice under handmade microscope Rice, a monocot, is normally grown as an annual plant, although in tropical areas it can survive as a perennial and can produce a ratoon crop for up to 30 years [3]. Rice cultivation is wellsuited to countries and regions with low labor costs and high rainfall, as it is labor-intensive to cultivate and requires ample water. However, rice can be grown practically anywhere, even on a steep hill or mountain area with the use of water-controlling terrace systems. Although its parent species are native to Asia and certain parts of Africa, centuries of trade and exportation have made it commonplace in many cultures worldwide. Production and consumption of rice is estimated to have been responsible for $4 \%$ of global greenhouse gas emissions in 2020.

\section{History and Origin of Rice}

Because of its long history and distinctiveness among crops, rice has been a part of human civilization for even millions of years [1]. It includes a vast variety of adaptations as well as a large range of genetic diversity in geological regions all over the world. The first progenitor of rice was a diversified grass in numerous humid locations of the southern continent known as Gondwana. As a result of the evolution of Gondwana species, the modern rice crop emerged. 0. sativa Land or Asian rice and O. glaberrima Steud or African rice, are the two primordial rice varieties that developed from Southeast Asia and West Africa, separately [2].

Domestic \& large-scale production methods in Africa and Asia have made rice types more diversified and healthy for rice-eating populations during the previous 12000 years. Genetic engineering \& transgenic approaches have resulted in a number of remarkable changes in rice plants, demonstrating progress in terms of maximal consumption [3]. Rice cultivation spanned 150 million hectares all across the world in 1994. Approximately 130 million acres of agricultural land were covered by Asian countries. Meanwhile, rice-growing land in South and North America comprised around 6 and 1.7 million ha, correspondingly. Approximately 7 million acres of African rice-producing land are on the back [4].

Rice cultivation has already spread throughout more than 100 nations around the world, from the South to the North Pole, between the latitudes of $40^{\circ} \mathrm{S}$ and $53^{\circ} \mathrm{N}$. In 1994, the overall paddy rice production worldwide was 534 million tons per annum [5], with Asia contributing roughly 482 million metric tons. In 1992, the United States harvested a record rice crop of 8.14 million $\mathrm{mt}$, making it the second most successful rice exporting country behind Thailand. Rice's global prominence has risen as a result of constant advancements in rice cultivation and harvesting techniques, making it as significant as wheat.

Despite the fact that wheat has somewhat greater cultivated acreage than rice, a large portion of wheat is used as animal feed, whereas rice is the only cereal plant consumed entirely by humans]6]. Rice output in the globe was expected to be over 553 million tonnes in 1996. Rice is expected to be used as a major food by more than a half of the world's population, making it the world's most important food crop. However, Asia, which is home to $60 \%$ (3 billion) of the world's population, cultivate and consume over 90 percent of the world's rice. China produces roughly 187 million of tons' rice, which is the world's greatest output, followed by India, which produces 122 billion tons. Indonesia and Bangladesh annually produce 50 to 27 million of tons' rice respectively [7]. Whereas Vietnam and Thailand are cultivating 24 to 21 million tons of rice correspondingly.

Rice output in the international trade sector accounted for just $4 \%$ of global production. Thailand is the largest rice supplier in these measures, with 4 to 6 million tons sold each year. Annually, Pakistan and Vietnam export approximately a million tons of rice. The demand for rice in Africa is rising at a $2 \%$ annual pace, while imports of rice reached approximately 3 million tons, accounting for only 25\% of global output. Saudi Arabia, Iran \& Iraq for example, import approximately $0.5,0.7$, and 0.9 million tons of rice per year, respectively [8].

Because the world's population is fast expanding and the world's rice trading receives only $5 \%$ rice, the productive need for wheat and rice is indeed increasing, and it appears that by 2020, four billion people would be reliant on these two essentials. Rice, according to the FAO, has exceeded wheat in demand and has become a component of high-calorie, 
high-energy diets in a variety of developing nations. Furthermore, it ranked first among dietary crops in the Asian regions [9].

\section{Morphology and physiology of Rice}

A hundred years ago, western intellectuals noted the significance of rice in their books \& tales set in the Southeast Asia. The majority of publications in China's and also the Indo-Pak subcontinent's ancient literatures address history of rice and categorization in various ways. Morphology knowledge, as well as structural conceptions and developmental research, are all interdisciplinary topics. It is quite beneficial in research to be familiar of morphological traits in order to better organize plant growth phases and enhance crop cultivation methods [10]. Rice plant that naturally grows in the form of grassy roots and culm, leaves, and glumes at the margins. During stunted and water floating situations, the height and breadth of different types of rice plants vary in the range of $0.4 \mathrm{~m}$ to $5 \mathrm{~m}$, depending on the environmental conditions. The following are some morphological characteristics:

\subsection{Roots of rice plant}

Rice is a member of the Graminae family, which means that all of its plants are monocotyledons having adventitious roots [11]. Rice plants produce main roots as a result of radical extension with the help of multiple adventitious roots. In comparison to taller cultivars, shorter types have less root penetration. Similarly, those types with good tillers also have a well-developed system of roots. Direct seeded crops have a deeper root system that is less developed, whereas transplanted seeded crops have a shallower root system that is more developed.

\subsection{Stems of rice plant}

Rice plant stems, or S. Oryzae, are similar to other grassland crops in that they have both a subterranean rhizome and an aerial false stem. In comparison to farmed rice, wild rice's perennial habitats have more of these characteristics (12). On the stems that stand above ground level, there are several solid nodes and some empty internodes known as culms. Internode length varies between species and as a result of environmental changes. The fast elongation of stems is caused by the emergence of panicles from rice flag leaves. Rice tillering behaviour was also linked to cultural activities, fertilization time, and variety [13]. Tillering begins after ten days of transplanting and reaches maximum growth in 4050 days.

\subsection{Leaves of rice plant}

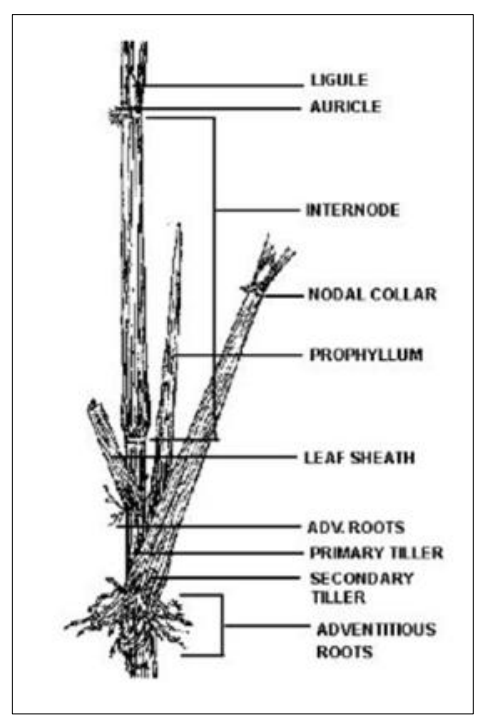

Figure 1 Morphology of Rice

Every node on the culm produces two tiers of rice plant leaves. Every leaf has a sheath as well as a lamina. The triangular collar can also be found at the point where the lamina and the leaf sheath meet. On the margins of the lamina, a couple of auricles in the form of a sickle, with a membranous ligule at the base of each collar. The ligule is usually 1 to $5 \mathrm{~mm}$ long in most rice species [14]. The swollen base of the sheath just above insertion point of the culm of leaves is known as pulvinus. The quantity of rice leaves reduces when the rice is organized by tillers. Flag leaves are the culm's terminal 
leaves that are positioned vertically and have a lamina that is shorter and wider than other leaves. The most essential leaves, known as prophyllus, encapsulate all the tillers that emerge from the rice stem's auxiliary buds.

\section{Rice plant flower}

Every rice spikelet has two infertile and two fertile glumes, as well as an inner palea and an exterior lemma. The lower perianth is made up of two fleshy and translucent structures called lodicules that are found at the base of each spikelet. Within every palea and lemma, around six stamens with a length of 2.0-2.5 mm are grouped in two whorls, with three stamens in each whorl. Rice flowers have a split stigma, a short rod-shaped style, and a purple-colored pistil with a single ovule [15]. The lemma of this flower has five separate palea and veins, whereas the glumes are usually empty or single nerved. In a few rice varieties, an awn develops regularly from the central vein of the lemma.

\subsection{Rice Taxonomy and Classification}

Rice is a member of the Oryzeae tribe of the Poaceae or Gramineae family, and it belongs to the kingdom's plantae Oryza genus [16]. This genus' plants may be found in a variety of tropical and subtropical regions all over the world. Just two species of rice crop, Oryza glaberrim and Oryza sativa, are farmed, while the rest 23 are found in the wild. 0. glaberrima and O. sativa are two cultivated species found on the African and Asian continents, respectively.

As per history and archaeology, 0. sativa evolved in South-east Asia as the principal centre, whereas 0. glaberrima evolved in Africa [17]. Furthermore, among all rice varieties, the 0 . perennis is regarded the most common progenitor plant. Similarly, the two other important species, O. nivira and O. rufipogan, are descended from O. sativa, whilst 0. longistaminata and 0 . barthii are 0. glaberrima's ancestors. For a long time, 0 . sativa, the famous geographical farmed specie, evolved three distinct subspecies due to varied changes in temperature and environment. O. sativa sub sp. Indica, 0 . sativa sub sp. Javanica, and 0 . sativa sub sp. Japonica are the names of these developed species [18].

\subsection{Rice Molecular Genetics}

Rice (Oryza sativa) is the most essential plant on the globe, since it provides 50 percent of the world's food and diet requirements. Several biological experts concentrated on the plant's emergence to study its helpful characteristics [19]. Its entire genome is roughly $4.3 \mathrm{MB}$ in size, which is three times that of A. thaliana, the most renowned plant in science, yet just a tenth of the human genome. Understanding of genetics and molecular biology is critical for improving the quality and quantity of crop yield and production [20]. During the diploid stage of Oryza sativa, 24 chromosomes are present in the paired form. In terms of physical traits, these chromosomes are further divided into three little pairs, four medium pairs, and five big pairs [21].

\section{Genome Wide Association and related Studies}

Rice's genome is tiny, making it easier to manage at the whole genome level. The GWAS allows us to concurrently test a large number of accessions for genetic variants that underpin several complex features. The advantages of the rice GWAS research are based on the homozygous nature of numerous rice types, which allows for the use of a genotype and phenotype several times [22]. When the lines are gnomically described using this method, the genetic data may be reprocessed numerous times over a wide range of phenotypic settings. If marker density \& LD (linkage disequilibrium) are high enough, complete genome association studies are likely to be effective.

Its goal was to increase the likelihood of random markers that are in disequilibrium with quantitative trait loci (QTLs) across diverse genetic materials [23]. Rice grain productivity and flowering period variables were previously studied using a GWAS with 950 recruitments. Many other crops, including as wheat, barley, sorghum, maize, and lettuce, have used this method. Meanwhile, extensive dissection of several maize features has been done using GWAS and genome sequencing [24]. Furthermore, there is a scarcity of knowledge on how to use genome-wide association studies to find molecular markers linked to several important rice attributes, notably by evaluating different authorizations in target rained environments [25].

GWAS are often used in diversity panels to gather diverse unlinked germplasms with the goal of increasing haplotype and allele diversity. While this is advantageous in terms of identifying new genetic markers and QTLs that activate desired agronomic features. Any identified QTLs must also be validated in breeding populations before they can be used for genomics-assisted selection. It is of importance to conduct GWAS in modified line populations for this reason [26]. QTL identified in this approach might be used more directly in genomic selection or MAS (marker assisted selection) in various applied breeding projects. (Jia et al., 2013). Genomic selection (GS), also known as genome wide 
prognostications, is a way of evaluating genome-wide DNA markers to forecast which individuals in a mating population would produce the most distinctive offspring in the next generation (27). The genome portion uses comparable inputs to GWAS in the form of a genotype and phenotype dataset on plant breeder populations of interest lines [28]. GS and GWAS can theoretically be performed on the same population, with all requirements being just extra computing analysis with significant benefits. The relationship between [29] GWAS, SNPs and QTLs related genes have been shown in figure.

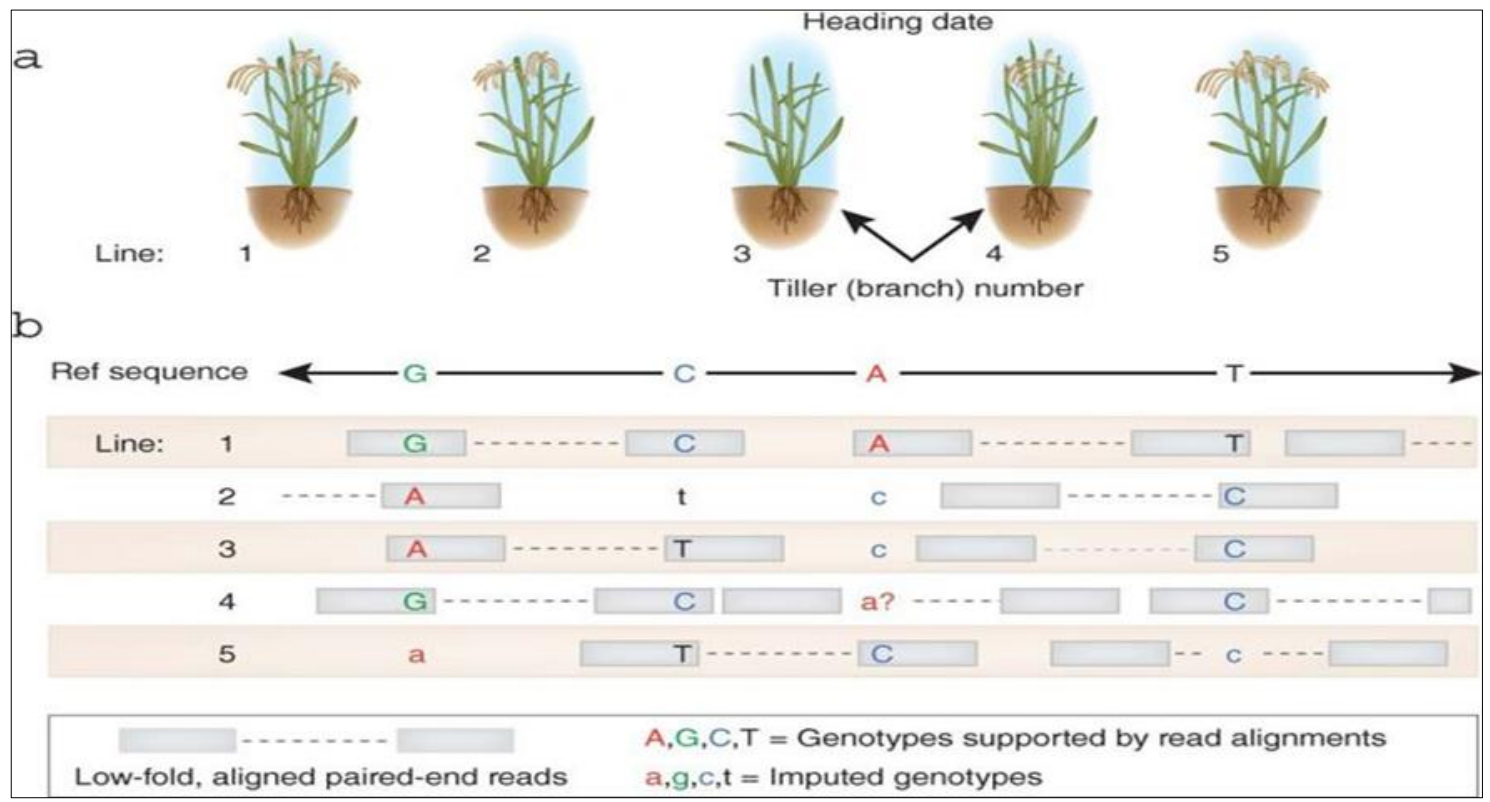

Figure 2 Genome Wide association of rice plants

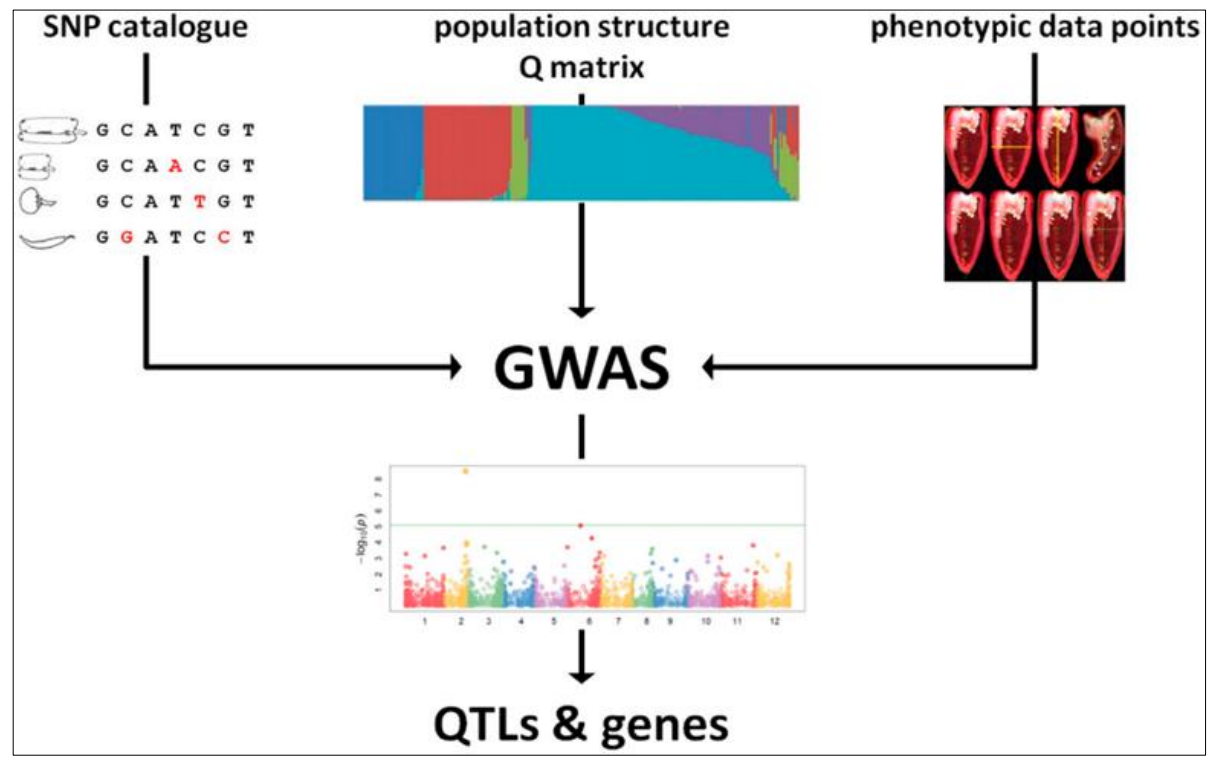

Figure 3 Relationship between GWAS, SNPs and QTLS

\section{RAPD \& PCR for Genome Wide studies}

Grain genotype identification has become more objective because to molecular marker procedures such as the PCR (polymerase chain reaction). The PCR method works by amplification of a particular sequence from genomic DNA [30], which may typically clarify polymorphisms within genotypes. The examination of amplification products may be an accurate tool for legal fortification of improved varieties by assessing purity, genetic distance, and solving parentage difficulties. Moreover, the inconsistency of the amplified product pattern might be used as a genetic marker in genome mapping investigations. PCR markers are also useful in molecular nomenclature and genetic diagnostic research [31]. 
For these types of analyses, just a small amount of plant components is required. This method's distinctions have been used to the study of inter- \& intera-specific polymorphism in cereal crops.

The study of similarities of genetics between germplasm genotypes among all kinds of plant species and the appraisal of phylogenetic connections have a variety of uses. Spotting phenotypes and calculating morphological features may be used to determine genetic diversity in plant varieties [32]. Despite, morphological and biochemical analysis provided a useful tool for studying genetics, but this technique has significant drawbacks, such as a limited number of enzymatic tests and phenotypic features. The use of molecular markers in molecular investigations has shown its utility for a number of purposes. Polymerase Chain Reaction improvement has greatly aided gene mapping, phylogenetic, and DNA fingerprinting research [33].

RAPD markers have also been used to identify and tag important genes for basmati rice quality features like prolongation of fried kernels, fragrance, starch content, and width and length fractions. Different types of genetic markers based on DNA have been used for the structure building of genetic maps, trait mapping, genetic diversity analysis, and applied diagnostics since their discovery in the last 20 years [34]. The relationship between Association mapping and markers associated study has been described in the figure.

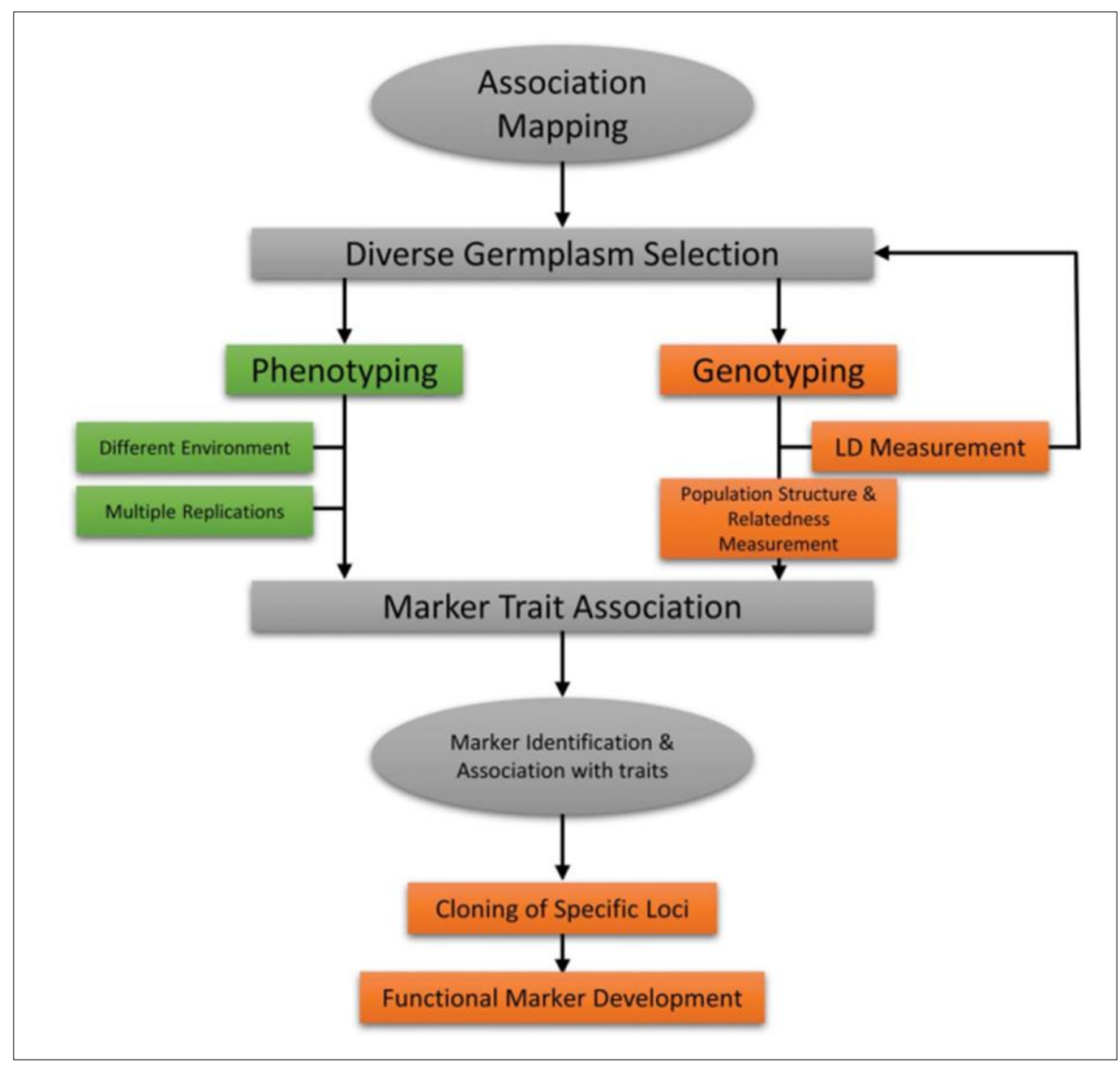

Figure 4 Relationship between Association mapping and markers associated study

For such goals, a bewildering array of acronyms has been developed, including (RFLP) Restriction fragment length polymorphism, restriction fragment RAPD Study [35], (AFLP) amplified fragments length polymorphism, (RAPD) random amplified polymorphic DNA, (SSR) simple sequence repeats, and others. The deployment of DNA-based genetic markers has firmly established genetics research procedures. Molecular techniques have proven useful in a variety of ways to improve plant genetic material management and conservation [36]. Plant breeders are interested in genetic markers as a source of genetic data on cereal crops and for using them in the marker - assisted selection of traits related with the markers. Plant breeders and farmers may use genetic variety to generate unique and high-yield crops 
that have resistance to virulent pathogens, as well as adaptive to changing conditions, via breeding and selection. The latent power of molecular approaches to develop dependable and resilient agricultural cultivars features that are suitable for database use and mainly modest in the environment has become more appealing. As a result, their potential for use in cultivar registration is being actively debated within the International Union for the Conservation of new plant varieties. As a result, there has been a significant increase in the use of biomarkers in breeding efforts for a variety of cereal crops in recent years [37]. Molecular markers not just to help in correlate the progression of novel diversities by reducing the time it takes to identify certain features in plant progenies, but they also help to identify resistance genes and associated molecular markers. As a result, marker aided selection may speed up the successful breeding of resistant characteristics into rice varieties [38].

Ten years ago, the RAPD approach seemed to be a viable alternative in the study of genetic links. Polymorphic band patterns are created using the polymerase chain reaction using different primers of DNA sequences. The random amplified polymorphic DNAs (RAPD) that have been separated by gel-electrophoresis after polymerase chain reaction using small random oligonucleotide primers. It has mostly been used in molecular and genetic investigations since it is a quick and easy way to recognize genetic diversity and similarities in a variety of species. RAPD also provides the advantage that no prior genomic information is required for study. It has been demonstrated that, despite the fact that AFLP analysis is more successful, RAPD may still be used as a consistent marker in small size labs [39].

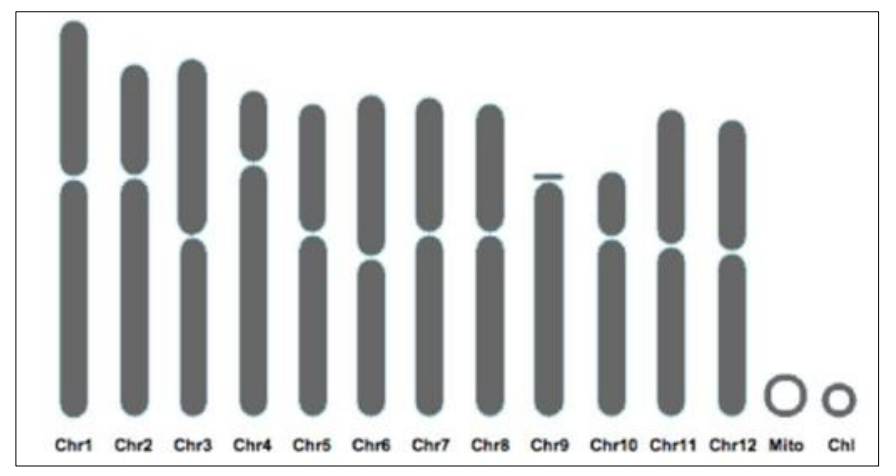

Figure 5 Chromosomes of Oryza sativa

0. sativa has a maximum chromosomal size of around 2.1 and a minimum size of about 1.4 . Wild rice species with $2 \mathrm{n}$ chromosomes, including 0 . coarctata, 0 . eichingeri, 0 . latifolia, as well as 0 . alta, usually produce tetraploid rice plants.

Table 1 lists some of the most important genetic characteristics of rice plants

Table 1 Genetic Characteristics

\begin{tabular}{|l|l|l|}
\hline Genetic Traits & Dominance & Recessiveness \\
\hline Awn & High awn & Non-awn \\
\hline Length of grains & Short & Long \\
\hline Height of Plant & Very tall & Very short \\
\hline Hairs on glumes & Pubescence & Smoothness \\
\hline Lodging & High lodging & Non- lodging \\
\hline Starch Situation & Starchy grains & Glutinous grains \\
\hline Panicle exertion & Exertion & No-Exertion \\
\hline
\end{tabular}

\section{The production of rice crop in Pakistan}

Pakistan is one of the most populous agricultural nations in South Asia, bordering the Arabian Sea to the south, China to the north, India to the east, Iran to the east \& Afghanistan to the west, Agriculture continues to play an important part in the region's economic growth and development [40]. Pakistan's gross domestic product (GDP) accounts for only 21.4 percent of the country's total. Furthermore, agriculture employs around 45 percent of the national work force and plays an important role in economic development. Pakistan's entire agricultural land area is estimated to be at 27.10 million hectares, with 1.644 million hectares of forest land [41]. Rice, wheat, maize, sugarcane, and cotton are the most 
significant crops. Just three crops account for around 5.4 percent of total GDP and provide 25.2 percent of the entire value of cereal crops agriculture. Rice has a distinct place among all of these crops, particularly grain-producing crops, and is therefore rated second among all cultivated crops after wheat. Only the rice harvest adds about 0.60 percent to Pakistan's GDP and 27 percent to the country's total agricultural growth [42].

Pakistan exports a large amount of rice every year since it is not a basic food in the country, and rice growing is done on 10percent of total cultivated area to increase foreign currency earnings. Before 1987-88, the (Rice Export Corporation of Pakistan) RECP had jurisdiction over rice exporting in Pakistan, but after that, this power was passed to the private sector for greater support and comparative improvements. The (Rice Exporters Association of Pakistan) REAP, as well as other government departments such as commerce, foods, agriculture, and livestock, are guiding that private sector business. Punjab is the most productive province in Pakistan, with 66.67 percent rice output and 53.19 percent rice cultivation area. According to Pakistan's 6th Census of Population and housing, the country's population is growing at a pace of 2.4 percent every year. It is increasingly growing the relevance of agricultural product requirements. Rice cultivation acreage has grown significantly as a result of improvements and contemporary technology [43], reaching 2,899 million ha in 2017-18, a rise of $6.4 \%$ over the previous year's area of 2,724 million ha.

\section{Aromatics Rice Varieties of Pakistan}

Aromatic rice types are distinguished by a unique combination of elements and have a well-known quality that is recognizable around the world, particularly in the United States, Europe, and the Middle East. Pakistan, India and Thailand are the key producing areas in this respect, with partnerships contributing to worldwide trade. In a variety of local folk legends, particularly Waris Shah's "Heer Ranja," the scent and quality features of fragrant rice harvests have been mentioned as Basmati, Zarda, Begmi and Mushkin words. The term Basmati is derived from two Hindi words: "Bas" which means fragrance and "Mati" which means May-up or origin, implying that it is a fragrant origin crop. The global market for these fragrant rice crops is estimated to be worth $\$ 500$ million each year [44].

\subsection{Basmati Rice}

Basmati rice, a kind of fragrant rice, is the most outstanding variety of rice in Pakistan. Taste, smell, and appearance are the three most influential variables in determining which rice qualities are of the highest standard. Basmati rice grains are satisfactory and have a lovely scent; including its subsequent type, jasmine rice, they account for 15 to18 percent of Pakistan's rice exports across the globe [45]. This type is mostly grown in tropical areas along the Ravi and Chenab rivers in the Gujrat, Nankana Sahib, Sheikhupura, Mandi Bahauddin, Gujranwala, Narowal and Hafizabad districts. During rainy season (July-August), this area receives 400-700 mm of rain and humidity. Basmati 2000 rice, Basmati 370 rice, Basmati 385 rice, Basmati 198 rice, including the most popular super basmati rice, Kisan basmati, Shaheen basmati rice, Kainat basmati and Kernal basmati rice have been cultivated in these regions for decades.

\section{Proteins and Metabolic Elements of Rice Crop}

The entire rice grains contain a huge number of proteins with important functional and structural features [46]. Brans, embryonic tissues, granules, and polishes, which contain vast amounts of storage proteins and starch bodies, are the sections of rice grains that preserve unique proteins. White rice protein (WRP) and rice bran protein (RBP), which are not found in maize or wheat grains, are the most outstanding and high-quality proteins found in rice crops [47]. The amino acid composition of rice bran proteins are identical to those of 2 to 5 year old soy proteins and caseins, both of which are regarded very nutritious and healthful sources of energy in human food.

Many proteins, such as globulin, prolamin, albumin, and glutelin, are abundant in rice plants and are classified based on particular characteristics such as composition and solubility of biochemical. When gibberellic acid transfer begins inside the embryonic seed's aleuronic layer during rice plant growth and development from an inactive form. The transcription of amylase proteins happens here, after which they are transmitted to the endosperm of a rice plant [48], which is rich in starch, and therefore energy is created for the growing embryo. Synthesis of hormones and protein are linked systems that are influenced by the presence of certain enzymes. The signal pathways of complex plants include a number of hormone proteins. The rice plant's gene expression system works in tandem with metabolism, stimulating mRNA to transcribe and codes for activated proteins.

The value of eatable ingredients is described by the starch of the rice plant [49]. The length and crystalline area of amylopectin chains of amino acids, the amount and solubility of amylose, and the melting temperature of the crystalline and indefinite structures of the rice plant are all typical parameters that impact the eating quality of rice. However, the rice crop's starch content contributes for around $95 \%$ of dry milling grain content [50]. Rice's sticky sur toughness is 
controlled by the quantity of protein in it; rice with a high protein level produces a finer crop than rice with a low protein content.

\section{Rice Genome sequencing}

Among some of the cereal crops, rice has a strong preference for its first full genome sequencing [51]. Rice's genome is thoroughly defined and sequenced, and it is the shortest of the main cereal crops' genomes, with an actual size of 400 to $430 \mathrm{Mb}$. Afterwards, the sorghum genome, with a size of 750 to $770 \mathrm{Mb}$, is the next biggest necessary cereal harvest genome, while the wheat genome, with a size of $16,000 \mathrm{Mb}$, is around 37 times larger than the rice genome (Figure 4). Wheat, rice, maize, sorghum, barley, and rye all have a lot of syntonic in their genomes, making rice an excellent model crop. Rice is also the easiest of the cereal crops to genetically modify. Despite the fact that the genome is only 430 megabytes in size, whole genome sequencing is a difficult task. Rice genome is approximately 3.5 times larger than Arabidopsis thaliana genome, and it is the third biggest public genome project completed to date, behind human and mouse genomes.

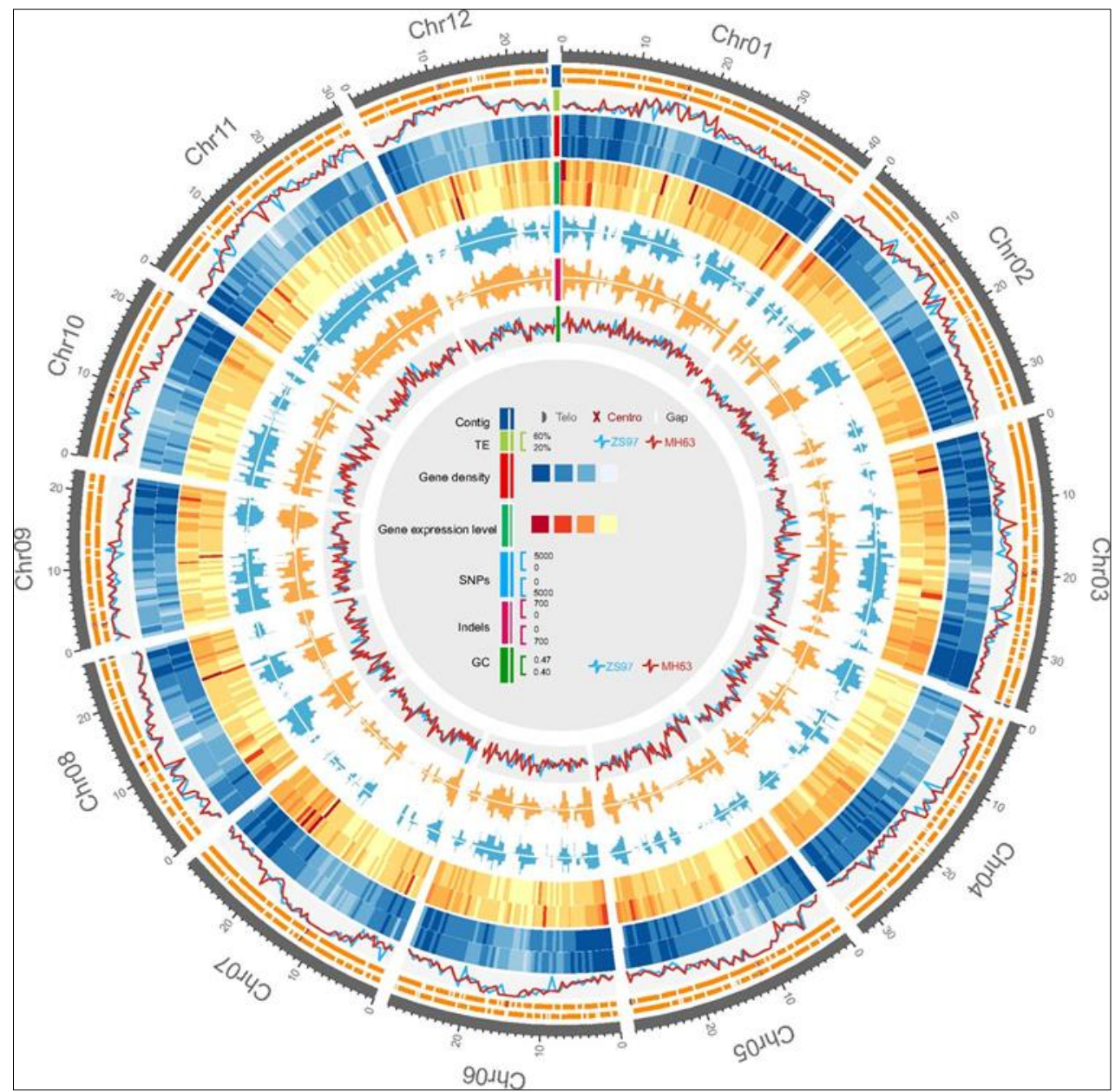

Figure 5 Rice Genome

The IRGSP (International Rice Genome Sequencing Project) began in Singapore in September 1997 during a workshop held in conjunction with the International conference on Plant Molecular Biology. Scientists from a variety of nations attended the workshop [52], which resulted in the formation of an international alliance to sequence the rice genome. As a consequence, after six months in Tsukuba, the contributing specialists from the U.S, Japan, the United Kingdom, Korea and China gathered to formulate the guidelines. The authors opted to pool resources and provide all physical maps and associated DNA sequences to online databases on a timely basis. The IRGSP has grown to include 11 nations, and the IRGSP working group, which consists of a single representative from each participating country, created the IRGSP finishing standards and rules. The genomic sequence breeding for crop improvement is enabled by the molecular characterization and genetic mapping of functioning genes that regulate disease resistance, efficiency of fertilizers and drought tolerance. 
Rice geneticists \& breeders have gathered a huge number of rice mutants over the past 100 years, and a conventional genetic map of rice has been built using phenotypic markers from these mutants. In comparison to other cereal crops, the compressed form of the rice genome provides a distinct advantage in gene isolation and genome sequencing [53], and the implications of rice genomics may be directly applied to cereal breeding. For these reasons, several organizations have identified rice as a priority species for genomic research. Advances in DNA technology have enabled to identify DNA variety in a wide range of plants. In 1988, a group of Cornell University researchers used the RFLPs (Restriction Fragment Length Polymorphisms) approach for the first time to build a rice linkage map, which was followed by the development of a fine linkage map using 726 DNA markers. A map of rice RFLP linkage has also been created by a group of Japanese researchers. The Japanese government funded a seven year RGRP (Rice Genome Research Program) to understand better the rice genome from 1991 to 1997.

\section{Rice Genomic Mapping}

Linkage mapping \& analysis are the most often used approaches for distinguishing complicated features. Linkage disequilibrium mapping, also known as association mapping, is a relatively new and capable genetic tool for dissecting complicated traits. It is a unique strategy for identifying genes that regulate major phenotypes. Based upon the of natural population research, association analysis is proven as an efficient tool for identifying genes that comprise critical traits. This mapping approach has the potential to provide greater resolution mapping by using historical recombination events at the level of population, which might enable mapping on the gene level with quasi animals when linkage-based methods are not possible. In order to deconstruct the diverse characteristics in crops, genomics, statistical, and genetic tools are used in association mapping. Natural diversity is being used to identify and exploit beneficial allelic variations for crop improvement. Figure 5 depicts the mapping of the rice genome.

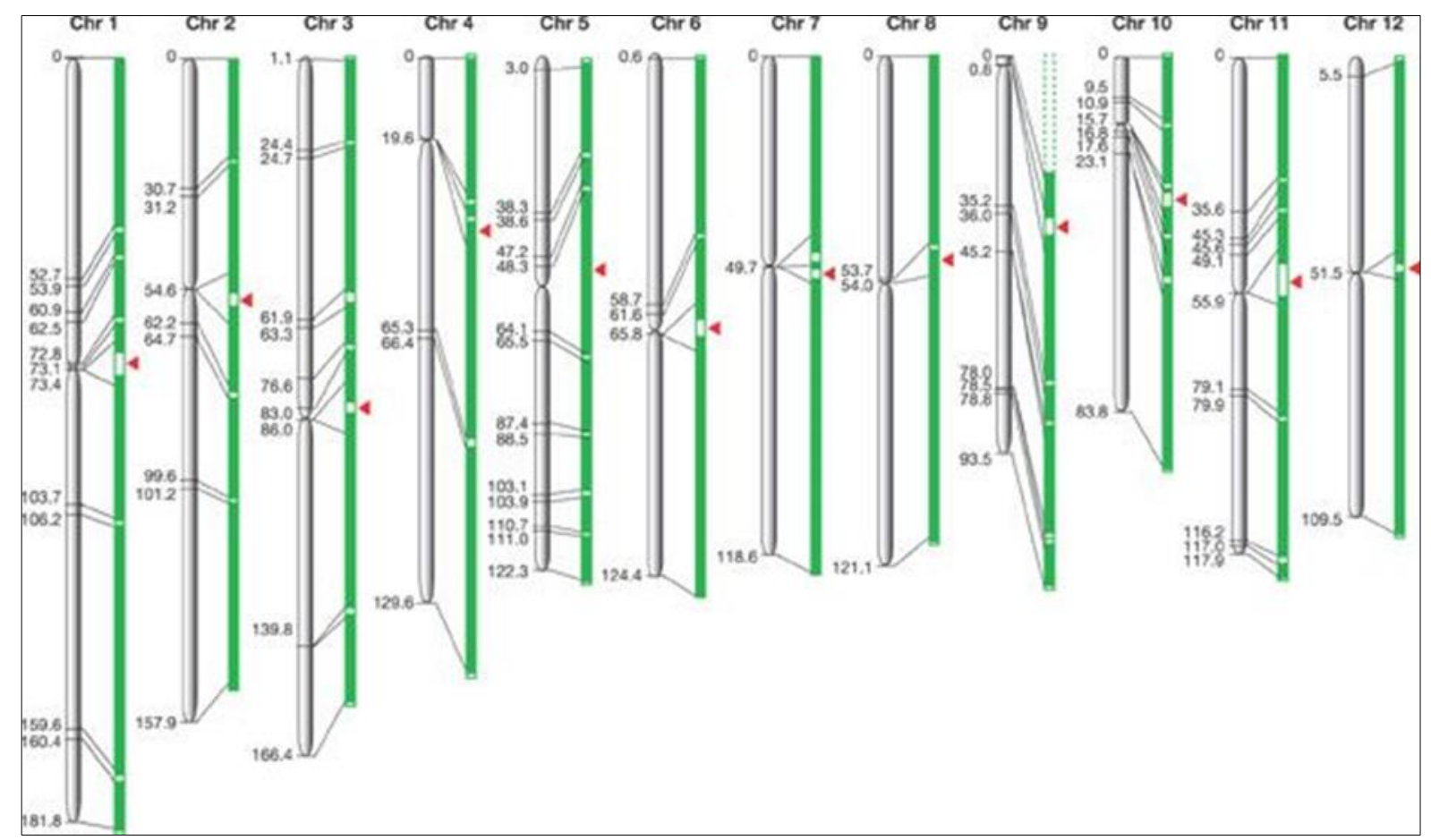

Figure 6 Rice Genome Mapping

However, the form of LD (linkage disequilibrium) across the genome determines the high-resolution mapping provided by association analysis. Linkage disequilibrium (LD) is a way of explicit alleles at various loci influencing unique genetic characteristics in populations that has traditionally been used at a lower degree of recombination. Although population history shapes LD patterns, other variables like as population form, mutation, selection, genetic drift, and related ness all have an influence on LD.

Furthermore, linkage-induced LD is the most important for association mapping. According to reports, the goal of association mapping, like linkage analysis, is to find relationships between genotypes \& phenotypic variability through linkage disequilibrium. Linkage analysis and association mapping are complementary methods that identify detailed chromosome areas of interest with relatively low marker coverage, meanwhile association mapping deals with greater 
resolution with either priori knowledge on a genome or candidate genes detected with some really high marker coverages [52],

SSR markers are extensively used in population \& relationship research because they are repeatable, multiallelic, PCRbased, and neutral selective. SSRs have mostly been utilized to characterize the population structure of rice. For accounting family relatedness and population structure, many statistical strategies have been proposed, including genomic controls, structured associations (SA), principal component technique, and mixed model approach. In crops of cereals, association mapping is just an active approach that connects structural phenomics to genomes. The individual markers that are spread throughout the genome association mapping may be effectively used to detect population structures thanks to the progress of statistical approaches. With the use of appropriate statistical tools and experimental designs, the concept of DNA markers based mapping is to detect relationships between markers and characteristics following linkage disequilibrium. Because of advancements in greater genome sequencing technology, interest in finding complicated, superior, and unique alleles, and improvements in statistical techniques, association mapping has continued to get increased attention in genetic research. The GWAS (genome-wide association study) has been advocated with the progress of next-generation sequencing to discriminate genes of agronomic features of rice in better resolution [53],

\section{Conclusion}

Oryza sativa is the most essential plant on the globe, since it provides 50 percent of the world's food and diet requirements. Domestic \& large-scale production methods in Africa and Asia have made rice types more diversified and healthy for rice-eating populations during the previous 12000 years. Genetic engineering \& transgenic approaches have resulted in a number of remarkable changes in rice plants, demonstrating progress in terms of maximal consumption. Rice cultivation spanned 150 million hectares all across the world in 1994. Approximately 130 million acres of agricultural land were covered by Asian countries. Meanwhile, rice-growing land in South and North America comprised around 6 and 1.7 million ha, correspondingly. Approximately 7 million acres of African rice-producing land are on the back. Rice's global prominence has risen as a result of constant advancements in rice cultivation and harvesting techniques, making it as significant as wheat. Because the world's population is fast expanding and the world's rice trading receives only $5 \%$ rice, the productive need for wheat and rice is indeed increasing, and it appears that by 2020 , four billion people would be reliant on these two essentials. Rice, according to the FAO, has exceeded wheat in demand and has become a component of high-calorie, high-energy diets in a variety of developing nations. Furthermore, it ranked first among dietary crops in the Asian regions. Rice's genome is tiny, making it easier to manage at the whole genome level. The GWAS allows us to concurrently test a large number of accessions for genetic variants that underpin several complex features. The advantages of the rice GWAS research are based on the homozygous nature of numerous rice types, which allows for the use of a genotype and phenotype several times. When the lines are gnomically described using this method, the genetic data may be reprocessed numerous times over a wide range of phenotypic settings.

\section{Compliance with ethical standards}

\section{Acknowledgments}

Many gratitude acknowledge to my Professor Dr. Muhammad Shahnawaz ul Rehman for supporting me in the field of science and technology.

\section{Disclosure of conflict of interest}

There is no conflict of interest to declare from anyone of authors.

\section{References}

[1] Khush GS. Origin, dispersal, cultivation and variation of rice. Plant molecular biology. 1997; 35(1): 25-34.

[2] Purseglove JW. The origins and migrations of crops in tropical Africa: De Gruyter Mouton. 2011.

[3] Vaughan DA, Lu B-R, Tomooka N. The evolving story of rice evolution. Plant science. 2008; 174(4): $394-408$.

[4] Hegde S, Hegde V. Assessment of global rice production and export opportunity for economic development in Ethiopia. Int J Sci Res. 2013; 2: 57-60.

[5] Chang T-T, Map UB. Origin, Domestication, and. Rice: Origin, history, technology, and production. $2002 ; 3: 3$. 
[6] Mercuri AM, Fornaciari R, Gallinaro M, Vanin S, Di Lernia S. Plant behaviour from human imprints and the cultivation of wild cereals in Holocene Sahara. Nature plants. 2018; 4(2): 71-81.

[7] Kahlon TS. Rice bran: production, composition, functionality and food applications, physiological benefits. Fiber ingredients: CRC Press. 2009; 319-36.

[8] Nigatu G, Motamed M. Middle East and North Africa Region: An Important Driver of World Agricultural Trade: United States Department of Agriculture, Economic Research Service. 2015.

[9] Shapouri S, Rosen S. Global diet composition: Factors behind the changes and implications of the new trends. Food Security Assessment. 2007; 28-36.

[10] Singh Y. Crop and water productivity as influenced by rice cultivation methods under organic and inorganic sources of nutrient supply. Paddy and Water Environment. 2013; 11(1): 531-42.

[11] Delseny M, Salses J, Cooke R, Sallaud C, Regad F, Lagoda P, et al. Rice genomics: present and future. Plant Physiology and Biochemistry. 2001; 39(3-4): 323-34.

[12] Mano H, Tanaka F, Nakamura C, Kaga H, Morisaki H. Culturable endophytic bacterial flora of the maturing leaves and roots of rice plants (Oryza sativa) cultivated in a paddy field. Microbes and Environments. 2007; 22(2): 17585 .

[13] Norman RJ, Wilson Jr CE, Slaton NA. Soil fertilization and mineral nutrition in US mechanized rice culture. Rice: Origin, history, technology, and production. 2003; 331-411.

[14] Sentoku N, Sato Y, Matsuoka M. Overexpression of rice OSH genes induces ectopic shoots on leaf sheaths of transgenic rice plants. Developmental biology. 2000; 220(2): 358-64.

[15] Geitmann A. Pollen and Pollen Tube Biology.

[16] Marsh J, Plowman L, Yamada-Rice D, Bishop J, Scott F. Digital play: A new classification. Early Years. 2016; 36(3): 242-53.

[17] Agnoun A, Samadori S, Biaou H, Sie M, Vodouhè R, Ahanchédé A. The African rice Oryza glaberrima Steud: knowledge distribution and prospects. International Journal of Biology. 2012.

[18] Hechanova SL, Bhattarai K, Simon EV, Clave G, Karunarathne P, Ahn E-K, et al. Development of a genome-wide InDel marker set for allele discrimination between rice (Oryza sativa) and the other seven AA-genome Oryza species. Scientific reports. 2021; 11(1): 1-11.

[19] Babu VR, Shreya K, Dangi KS, Usharani G, Nagesh P. Genetic variability studies for qualitative and quantitative traits in popular rice (Oryza sativa L.) hybrids of India. International Journal of Scientific and Research Publications. 2012; 2(6): 1-5.

[20] Khush GS. Strategies for increasing the yield potential of cereals: case of rice as an example. Plant Breeding. 2013; 132(5): 433-6.

[21] Yi C, Hu D, Zhang J, Jin W, Li W, Zhou Y, et al. Development and identification of synthetic interspecific hybrids between Oryza sativa and Oryza australiensis. Indian J Genet. 2018; 78(2): 174-9.

[22] Huang X, Yang S, Gong J, Zhao Y, Feng Q, Gong H, et al. Genomic analysis of hybrid rice varieties reveals numerous superior alleles that contribute to heterosis. Nature communications. 2015; 6(1): 1-9.

[23] Fresnedo-Ramírez J, Frett TJ, Sandefur PJ, Salgado-Rojas A, Clark JR, Gasic K, et al. QTL mapping and breeding value estimation through pedigree-based analysis of fruit size and weight in four diverse peach breeding programs. Tree Genetics \& Genomes. 2016; 12(2): 25.

[24] Mir RR, Reynolds M, Pinto F, Khan MA, Bhat MA. High-throughput phenotyping for crop improvement in the genomics era. Plant Science. 2019; 282: 60-72.

[25] Tam V, Patel N, Turcotte M, Bossé Y, Paré G, Meyre D. Benefits and limitations of genome-wide association studies. Nature Reviews Genetics. 2019; 20(8): 467-84.

[26] Heslot N, Jannink JL, Sorrells ME. Perspectives for genomic selection applications and research in plants. Crop Science. 2015; 55(1): 1-12.

[27] Spindel J, Iwata H. Genomic selection in rice breeding. Rice genomics, genetics and breeding: Springer. 2018; 47396. 
[28] Tung C-W, Zhao K, Wright MH, Ali ML, Jung J, Kimball J, et al. Development of a research platform for dissecting phenotype-genotype associations in rice (Oryza spp.). Rice. 2010; 3(4): 205-17.

[29] Geng X, Sha J, Liu S, Bao L, Zhang J, Wang R, et al. A genome-wide association study in catfish reveals the presence of functional hubs of related genes within QTLs for columnaris disease resistance. BMC genomics. 2015; 16(1): $1-12$.

[30] Farrar JS, Wittwer CT. Extreme PCR: efficient and specific DNA amplification in 15-60 seconds. Clinical chemistry. 2015; 61(1): 145-53.

[31] Saidi A, Eghbalnegad Y, Hajibarat Z. Study of genetic diversity in local rose varieties (Rosa spp.) using molecular markers. Banat's Journal of Biotechnology. 2017; 8(16): 148-57.

[32] Mitema A, Okoth S, Rafudeen MS. Vegetative compatibility and phenotypic characterization as a means of determining genetic diversity of Aspergillus flavus isolates. Fungal biology. 2018;122(4): 203-13.

[33] Kumar M, Pawar SV, Masurkar P, Choudhary S. Molecular markers: A new frontier approaches in crop improvement. IJCS. 2017; 5(4): 1724-9.

[34] Alhasnawi AN, Kadhimi AA, Isahak A, Ashraf MF, Doni F, Mohamad A, et al. Application of inter simple sequence repeat (ISSR) for detecting genetic analysis in rice (Oryza sativa L.). Journal of Pure and Applied Microbiology. 2015; 9(2): 1091-101.

[35] Zakiyah NM, Handoyo T, Kim K-M. Genetic diversity analysis of Indonesian aromatic rice varieties (Oryza sativa L.) using RAPD. Journal of Crop Science and Biotechnology. 2019; 22(1): 55-63.

[36] Gurr GM, You M. Conservation biological control of pests in the molecular era: new opportunities to address old constraints. Frontiers in plant science. 2016; 6: 1255.

[37] Sulpice R. Closing the yield gap: can metabolomics be of help? Journal of experimental botany. 2020; 71(2): 4614.

[38] Ellur RK, Khanna A, Yadav A, Pathania S, Rajashekara H, Singh VK, et al. Improvement of Basmati rice varieties for resistance to blast and bacterial blight diseases using marker assisted backcross breeding. Plant Science. 2016; 242: 330-41.

[39] Dhakshanamoorthy D, Selvaraj R, Chidambaram A. Utility of RAPD marker for genetic diversity analysis in gamma rays and ethyl methane sulphonate (EMS)-treated Jatropha curcas plants. Comptes rendus biologies. 2015; 338(2): 75-82.

[40] Pribadi DO, Pauleit S. The dynamics of peri-urban agriculture during rapid urbanization of Jabodetabek Metropolitan Area. Land use policy. 2015; 48: 13-24.

[41] Ghafoor A, ur Rehman T, Munir A, Ahmad M, Iqbal M. Current status and overview of renewable energy potential in Pakistan for continuous energy sustainability. Renewable and Sustainable Energy Reviews. 2016; 60: 133242.

[42] Dawe D. Agricultural transformation of middle-income Asian economies: diversification, farm size and mechanization. 2015.

[43] Ghimire R, Wen-Chi H, Shrestha RB. Factors affecting adoption of improved rice varieties among rural farm households in Central Nepal. Rice Science. 2015; 22(1): 35-43.

[44] Bhuvaneshwari S, Hettiarachchi H, Meegoda JN. Crop residue burning in India: policy challenges and potential solutions. International journal of environmental research and public health. 2019; 16(5): 832.

[45] Abdullah M, Li J, Ghazanfar S, Ahmed J, Khan I, Ishaq MN. Where Pakistan stands among top rice exporting countries, an analysis of competitiveness. Journal of Northeast Agricultural University (English Edition). 2015; 22(2): 80-6.

[46] Meher PK, Sahu TK, Saini V, Rao AR. Predicting antimicrobial peptides with improved accuracy by incorporating the compositional, physico-chemical and structural features into Chou's general PseAAC. Scientific reports. 2017; $7(1): 1-12$.

[47] Phongthai S, Homthawornchoo W, Rawdkuen S. Preparation, properties and application of rice bran protein: A review. International Food Research Journal. 2017; 24(1): 25.

[48] Pfister B, Zeeman SC. Formation of starch in plant cells. Cellular and Molecular Life Sciences. 2016; 73(14): 2781807. 
[49] Ogawa Y, Donlao N, Thuengtung S, Tian J, Cai Y, Reginio Jr FC, et al. Impact of food structure and cell matrix on digestibility of plant-based food. Current opinion in food science. 2018; 19: 36-41.

[50] Arribas C, Cabellos B, Sánchez C, Cuadrado C, Guillamón E, Pedrosa M. The impact of extrusion on the nutritional composition, dietary fiber and in vitro digestibility of gluten-free snacks based on rice, pea and carob flour blends. Food \& function. 2017; 8(10): 3654-63.

[51] Du H, Yu Y, Ma Y, Gao Q, Cao Y, Chen Z, et al. Sequencing and de novo assembly of a near complete indica rice genome. Nature communications. 2017; 8(1): 1-12.

[52] Vetter JS, Brightwell R, Gokhale M, McCormick P, Ross R, Shalf J, et al. Extreme heterogeneity 2018-productive computational science in the era of extreme heterogeneity: Report for DOE ASCR workshop on extreme heterogeneity. 2019.

[53] Si L, Chen J, Huang X, Gong H, Luo J, Hou Q, et al. OsSPL13 controls grain size in cultivated rice. Nature genetics. 2016; 48(4): 447-56. 